it may be divided naturally into two portions with the boundary about Tahiti. In the eastern portion the amount of oxygen diminishes very rapidly with the depth down to the minimum at 400-500 m., thereafter increasing again towards the bottom, where increasingly higher values are obtained the farther one goes westwards.

On the other hand, in the western portion of the section we find a slower decrease in the amount of oxygen with the depth, until a minimum is reached at c. 2000-2500 m., after which it again increases gradually towards the bottom. This minimum, however, is not nearly so well marked as the minimum in the eastern portion, the saturation percentage not going below 40 per cent. Thus, whilst the saturation percentage in the western portion is everywhere greater than 40 per cent, throughout the eastern portion it is less, with the exception of a surface layer of small extent and the bottom water in the part of the section which lies west of long. $120^{\circ} \mathrm{W}$.

These conditions agree well with what one might have expected beforehand. In tropical seas, with high temperature and relatively low salinity at the surface, the density of the surface water will be so much less than that of the layers below that the descent of oxygen to the latter by vertical convection currents cannot take place. An addition of oxygen to the deeper layers in the equatorial zone must therefore come from meridional currents, which will be deflected westwards with the earth's rotation and thus come to have a stronger influence in the western than in the eastern portion of the ocean. Hence the supply of oxygen will be greatest in the western portion, in agreement with the above section.

It may be noted, however, that this section does not follow the same degree of latitude, extending as it does from lat. $7^{\circ} \mathrm{N}$. in the eastern portion to lat. $23 \frac{1}{2}^{\circ} \mathrm{S}$. in the western portion. If the indicated supply of oxygen to the equatorial zone takes place from the south, as the available hydrographical data suggest, this in itself would cause the western portion of the section to contain more oxygen than the eastern portion, and we should expect that a section due west from the Gulf of Panama would contain less oxygen than the foregoing. Other observations indicate that this view is very probable. For example, the American Carnegie Expedition, working in these waters a year after the Dana, found an oxygen minimum of 0.5 to 1 per cent in depths between $100 \mathrm{~m}$. and $400 \mathrm{~m}$. at $c$. lat. $12^{\circ} \mathrm{N}$. and long. $137^{\circ} \mathrm{W} .{ }^{4}$ This minimum is of the same dimension as that found by the Dana expedition at Panama and considerably less than the minimum measured by the Dana on the same degree of longitude but some twenty degrees more to the south.

In July 1929, when the Dana expedition was working in the waters north of New Guinea, an oxygen minimum of $27 \cdot 3$ per cent was found in $400 \mathrm{~m}$. at lat. $3^{\circ} 40^{\prime} \mathrm{N}$. and long. $137^{\circ} 40^{\prime} \mathrm{E}$. These observations afford strong support to the view that the layer poor in oxygen, which was first noticed by the Dana in 1922 in the Gulf of Panama, is centred about lat. $5^{\circ}$ to $10^{\circ} \mathrm{N}$. and extends at a depth of about $400 \mathrm{~m}$. right across the whole Pacific, though the minimum becomes less marked the farther we go westwards, yet still about 27 per cent in the westernmost part. It is worth remarking that this oxygen minimum has about the same geographical distribution as the equatorial countercurrent. The existence of the very poor oxygen layer under the latter shows that in these depths the currents with a meridional component must be extremely weak.

In conclusion it may be mentioned that a somewhat similar oxygen distribution was found in the tropical part of the Atlantic in 1926 by the German Meteor Expedition, ${ }^{5}$ and, though less strongly marked, in 1921 by the Dana along a section from Cape Verde Islands to Cayenne. ${ }^{6}$ Further, an intermediate oxygen minimum was found by the Dana in the tropical Indian Ocean during the Circumnavigation Expedition in 1929. There seems to be no doubt, therefore, than an intermediate oxygen minimum extends as a belt round the globe in the equatorial zone.
1 Vidensk. Med. Dansk Nat. For., vol. 90, p. 371; Copenhagen, 1931.
${ }^{2}$ See inter alia "The Distribution of the Pelagic Fry of the Gadoids in the North Atlantic from Iceland to Spain" (Conseil Internationa
pour l' Exploration de la mer, vol. 10, No. 4; Copenhagen, 1909). sides of Panama" (Science, June 5, 1925). Idem, "Introduction to the Oceanographical Reports", The Danish Dana Expeditions, 1920-22 in the North Atlantic and the Gulf of Panama. Copenhagen and London, 1929.
* Department of Terrestrial Magnetism. Carnegie Institution of Washington: Reports and Communications to Section of Oceanography.
Washington D.C., June 30, 1930. . (Journal du Conseil International, vol. 4, No. 1, Copenhagen, 1929).
J. P. Jacobsen, "Contribution to the Hydrography of the North Atlantic". The Danish Dana Expeditions, 1920-22, in the North Atlantic and the Gulf of Panama, No. 3, Copenhagen and London, ibid., No. 1, Copenhagen and London, 1929.

\title{
The Nature and Scope of Physical Science.*
}

I.

\section{By Prof. Herbert Dingle.}

GCIENCE may be defined as the recording, $\$$ augmentation, and rational correlation of those elements of our experience which are actually or potentially common to all normal people. The phrase cannot boast of elegance, but for clear thinking, rigidity and conciseness are the important considerations.

* Substance of a course of four lectures delivered at the Royal Institution on Jan. 22, 29, Feb, 5 and 12 .
To prevent excessive misunderstanding, some explanations are necessary, which limits of space compress to the barest minimum. By 'experience' is meant everything of which we are conscious except rational conceptions. Experiences ' common to all normal people' may for practical purposes be thought of as observations made by means of the senses, but since what fits them for scientific discussion is not the way in which we get them

No. 3204, Vor. 127] 
but the fact that they are universal, the more general description is preferable. By expressing the data of science as experiences and not as the external world giving rise to them, we evade the problem of the objectivity of that world; that is a problem for philosophy, not for science. Finally, the word 'potentially' is inserted in the definition merely to include observations which might be made but are not; it is not a loophole for the admission of hypothetical experiences which future developments of the human organism might make possible.

The definition limits science only in respect to its data and its purposes; it imposes no limitation on method. As a historical fact, of course, science has almost invariably restricted itself to the familiar processes of observation and experiment for the accumulation of its data, and to abstraction and hypothesis for their rational correlation. It is conceivable, however, that science might be advanced by other means, for example, clairvoyance; but if such means are employed, their indications must always be confirmed by common observation before they are accepted as a part of science.

Nevertheless, in the history of science, the methods of abstraction and hypothesis have been of the utmost importance, and the significance of physics at the present day has, I think, been widely misunderstood through a misapprehension of their essential nature. Let us look at them a little more closely.

Abstraction is the detection of a common quality in the characteristics of a number of diverse observations; it is the method supremely exemplified in the work of Newton and Einstein. Newton, for example, gave us ' laws of motion'. Now, motion is not an experience; what we observe are moving bodies. Motion is an abstraction, a quality conceived to be possessed by all moving bodies, however much they may differ in size, shape, colour, beauty, virtue, or anything else. The laws of motion express the characteristics of this common quality, and they are therefore a rational means of correlating a vast body of common experience.

A hypothesis serves the same purpose, but in a different way. It relates apparently diverse experiences, not by directly detecting a common quality in the experiences themselves, but by inventing a fictitious substance or process or idea, in terms of which the experiences can be expressed. A hypothesis, in brief, correlates observations by adding something to them, while abstraction achieves the same end by subtracting something. For example, to correlate the motion of Uranus with that of the other planets by abstraction in the year 1845 would have been a terrifying business. The simpler plan was adopted of supposing the existence of another planet which, with Uranus, obeyed the laws of motion abstracted from the behaviour of the more familiar planets, and the problem was solved.

A hypothesis of this kind can be "proved to be true ". That is, of course, what occurred in the example just given, which led directly to the discovery of the planet Neptune. But there are other hypotheses which cannot be thus verified; for example, the supposed birth of the planets through the influence of a passing star. This is not the only, nor at the moment the most conspicuous, type of unverifiable hypothesis, but we shall return to this point later.

The mental processes involved in abstraction and the formulation of hypotheses can be traced back through the ages. At the beginning of modern physics, however, only the method of abstraction was employed. Newton was the sworn foe of hypotheses. The elements of his philosophy -mass, force, absolute space and time-were abstractions from observations, in terms of which the processes of the physical world were described. He always strenuously opposed the imputation that he employed hypotheses, and although nowadays it is commonly stated that gravitation, for example, is a hypothesis, it could be shown, if space permitted, that it expresses nothing more than is actually contained in observation; that is, it is an abstraction. The same method has now been applied to a more extensive field of observation by Einstein, and the theory of relativity is a pure abstraction after Newton's own heart. The equations of the electro-magnetic field, the principle of the conservation of energy, and the second law of thermodynamics are other examples of abstraction in physics.

The great influence of Newton dominated the activities of physicists and mathematicians during the eighteenth century, and the progress of that time is summed up partly in the successful application of his principles to detailed phenomena and partly in the reformulation of his essential ideas into alternative expressions more convenient for certain calculations. Hypotheses were at a discount. But, fortunately for science, other influences were independently at work which, so far as physical science is concerned, found the most effective medium of operation in chemistry. Chemistry, no less than physies, had throughout the Middle Ages been held back by the arbitrary adoption of 'principles' and 'occult qualities', but it had suffered nomartyrdom such as had canonised physics and astronomy in the person of Galileo. It had therefore no need of a formal body of doctrine, and while it could profit by the purifying influence of the great physicists, it could also regard with tolerance what to them was heresy. Consequently we find chemistry freeing itself from superstition more gradually than physics, but at a smaller cost. Thus, while Newton was declaiming against hypotheses, Stahl was conjuring up the spirit of phlogiston which was to direct chemical progress for the next hundred years. This freedom of chemistry to be influenced, but not controlled, by the mathematical revolution is of the utmost importance, for by the gradual merging of the two sciences into one, physics has slowly become emancipated from the restrictions which Newton imposed, although whether she has done so without sacrificing the principles for the sake of which he imposed them is a matter of grave doubt.

I have neither space nor knowledge to trace in detail the introduction of hypotheses into physics. 
To illustrate the process, however, here are three quotations from representative men of science, covering the period from Newton to the present time and separated by roughly equal intervals. The first is from Newton himself (1687) : "I frame no hypotheses. For whatever is not deduc'd from the phænomena, is to be called an hypothesis; and hypotheses, whether metaphysical or physical, whether of occult qualities or mechanical, have no place in experimental philosophy." The second is from Laplace (1796): "I will suggest an hypothesis which appears to me to result with a great degree of probability, from the preceding phenomena, which, however, I present with that diffidence, which ought always to attach to whatever is not the result of observation and computation". The third is from Eddington (1926): "Care is taken to provide 'macroscopic' equations for the human scale of appreciation of phenomena as well as 'microscopic ' equations for the microbe. But there is a difference in the attitude of the physicist towards these results; for him the macroscopic equations-the large-scale results--are just useful tools for scientific and practical progress ; the microscopic view contains the real truth as to what is actually occurring." The direction of development is obvious, and its validity is the most vital question, both for the philosophy of science and for the application of scientific ideas to other departments of thought, at the present time.

The introduction of the atomic hypothesis into physics raises the question of the significance to be ascribed to hypotheses which postulate entities (such as atoms and electrons) which are essentially unobservable. I think the conclusion is inescapable that such entities can be regarded only as concepts, possessing no properties and subject to no laws other than those which are necessary and sufficient to enable them to correlate observations. The question whether they are real or not is already answered in the designation of them, for we can scarcely regard anything as real, in the sense in which observed existences are real, which is essentially unobservable. If we adopt such hypotheses, therefore, we have perfect freedom to shape them as we please, provided they achieve the end for which they were created. We are not bound to give them the characteristics of phenomena. They are employed for rational correlation and are not admissible to experience; they must therefore have rational properties, but not necessarily sensible ones.

This, however, was overlooked by the physicists of the early twentieth century, who appeared to be faced by an irresolvable dilemma in the inability of the atom to emit radiation without self-destruction. The position was that either the solar system model of the atom, to which the development of the atomic hypothesis had apparently inevitably led, or the laws of electro-magnetism, abstracted from phenomena, had to be left out of consideration if the atomic hypothesis was to be extended to include the interaction of matter with radiation; and physicists in general were willing to abandon neither. Why was this ?

It was simply that they did not realise the essential character of a hypothesis. The atoms, being hypothetical units, were in their hands to mould to the dictates of their imaginations, and they did not know their own freedom. They thought of atoms, not as hypotheses but as potential phenomena and therefore necessarily subject to the laws already established for phenomena by the method of abstraction. The process began when atoms were first introduced into physics. At that time they were supplied instinctively with mass and the other Newtonian abstracted qualities, and the implication that they were potential phenomena took such hold of succeeding physicists that by the twentieth century its arbitrariness needed a genius to perceive it. Fortunately the genius, in the person of Neils Bohr, was at hand. Bohr retained the solar system model of the atom, but absolved it from obedience to the laws of electromagnetism.

This step of Bohr's was the most significant in physical science since the introduction of the bypothesis of atoms. What virtually it did was to establish the fact that the hypothetical atoms were pure conceptions : that they belonged essentially to a different category from the facts of observation. They were creatures of the imagination, to be formed into the image of our fancies and restricted by whatever laws we cared to prescribe, provided only that when they behaved in accordance with those laws they should reproduce phenomena. 'They were removed from the realm of experience and deposited in that of reason.

Developments have succeeded one another with almost alarming rapidity, but from the fundamental point of view nothing new has happened. The solar system model has gone and a conception devoid of any pictorial aspect has taken its place, but that-if in so speaking we may disclaim any disrespect to the brilliant physicists who have organised the process - is but the ass's kick at the dead lion. Whatever formal doctrine physicists may profess, they exhibit in practice no more belief in the phenomenal reality of atoms than in the philosopher's stone.

\section{News and Views.}

The Duddell Medal for 1930 of the Physical Society was presented to Sir Ambrose Fleming at the annual general meeting of the Society on Mar. 20. The medal is awarded not more frequently than once a year to persons who have contributed to the advancement of knowledge by the invention or design of scientific instruments or by the discovery of materials used in their construction. Sir Ambrose Fleming's connexion with the Physical Society dates back to its very beginning, for he read the first paper at the inaugural meeting of the Society in March 1874. In 1879, Sir Ambrose designed a special form of resistance balance for comparing standard coils, and a special form of standard coil capable of taking up 